\title{
PREFERENSI DAN TANGGAP FUNGSIONAL PARASITOID HEMIPTARSENUS VARICORNIS (GIRAULT) (HYMENOPTERA: EULOPHIDAE) PADA LARVA LALAT PENGOROK DAUN KENTANG
}

\author{
Hidrayani $^{1}$, Aunu Rauf ${ }^{2}$, Soemartono Sosromarsono ${ }^{2}$, dan Utomo Kartosuwondo ${ }^{2}$
}

\begin{abstract}
The preference and functional response of Parasitoid Hemiptarsenus varicornis (Girault) (Hymenoptera:Eulophidae) on host larvae of potato leafminers. The preference of Hemiptarsenus varicornis (Girault) on host larvae of potato leafminers (Liriomyza huidobrensis) and their functional response on host abundance were studied in laboratory. The preference test was conducted by releasing a female parasitoid in a cage containing two redbean leaves, one with $2^{\text {nd }}$ instar and another one with $3^{\text {rd }}$ instar. The functional response test was conducted by providing $3^{\text {rd }}$ instar with density $1,4,6,8,10$, and 13 larvae per leaf. The result showed that $H$. varicornis had the preference on $3^{\text {rd }}$ instar larvae compared to $2^{\text {nd }}$ instar, either for parasitisation or paralysis. Based on logistic regression analysis it was found that the parasitoid showed type II functional response on the increase of host abundance. The searching rate (a) and handling time (Th) for paralysis were 0.038 and 1.473 based on disk equation model, and 0.076 and 2.060 on ramdom equation model. For parasitisation activity, the value of a and Th were 0.012 and 4.649 based on disk equation model, and 0.014 and 5.075 on random equation model.
\end{abstract}

Key words: Hemiptarsenus varicornis, host preference, functional response

\section{PENDAHULUAN}

Penggunaan parasitoid merupakan salah satu alternatif dalam pengendalian hayati lalat pengorok daun kentang, Liriomyza huidobrensis (Blanchard) (Diptera: Agromyzidae). Salah satu parasitoid yang umum ditemui memarasit hama tersebut ialah Hemiptarsenus varicornis (Girault) (Hymenoptera: Eulophidae) (Rauf et al., 2000; Supartha, 1998). Banyak hal yang perlu diketahui mengenai kehidupan parasitoid tersebut agar dapat digunakan secara tepat dalam program pengendalian hayati hama pengorok daun. Pemilihan terhadap instar inang dan tanggap fungsional $H$. varicornis belum pernah dilaporkan. Supartha (1998) menemukan bahwa dari tiga instar larva L. huidobrensis, instar -2 dan -3 adalah fase yang dipilih oleh $H$. varicornis, tetapi belum diketahui instar yang paling disukai. Padahal instar inang mempengaruhi keberhasilan perkembangan parasitoid (Fuester \& Taylor 1991; Rustam, 2002).

Tanggap fungsional merupakan salah satu ukuran untuk menentukan keefektifan suatu parasitoid sebagai agens dalam pengendalian hayati (Doutt, 1973). Istilah tanggap fungsional menyatakan perubahan jumlah mangsa yang diserang oleh individu predator akibat perubahan kerapatan populasi mangsa per satuan waktu
(Berryman, 1981; Hassell, 2000). Tanggap fungsional diklasifikasikan oleh Holling ke dalam tiga tipe umum, yaitu tipe tanggap fungsional linear (Tipe I), hiperbolik (Tipe II) dan sigmoidal (Tipe III) (Hassell, 2000).

Untuk analisis tanggap fungsional predator, terdapat dua pendekatan yaitu dengan persamaan cakram (disc equation) (Holling 1959) dan persamaan acak predator (random predator equation) (Rogers, 1972). Persamaan cakram digunakan bila selama percobaan berlangsung dilakukan penggantian mangsa yang mati, dan bila tidak dilakukan penggantian, digunakan persamaan acak. Untuk tanggap fungsional parasitoid, perlu diberikan pertimbangan dalam memilih pendekatan yang lebih cocok, sesuai dengan perilaku parasitoid yang dipelajari.

Sehubungan dengan perilaku parasitoid $H$. varicornis yang melakukan pelumpuhan (paralisis) sebelum oviposisi dan pelumpuhan tanpa diikuti oviposisi, yang keduanya menyebabkan kematian, perlu dipelajari tanggap fungsionalnya secara terpisah menurut sebab kematiannya. Dalam hal ini tanggap fungsional dibedakan atas tanggap fungsional pelumpuhan (total mortalitas) dan tanggap fungsional parasitisasi. Penelitian bertujuan menentukan preferensi parasitoid betina $H$. varicornis terhadap instar larva inang dan mengkaji tanggap fungsional parasitoid tersebut pada berbagai kerapatan inang.

\footnotetext{
${ }^{1}$ Jurusan Hama dan Penyakit Tumbuhan, Fakultas Pertanian, Universitas Andalas, Padang, 25163, Telp. 0751-72702

${ }^{2}$ Departemen Proteksi Tanaman, Fakultas Pertanian, IPB, Jl. Kamper Kampus Darmaga Bogor 16680
} 


\section{METODE PENELITIAN}

Penelitian dilaksanakan di Insektari Jurusan Proteksi Tanaman, Fakultas Pertanian - IPB. Suhu ruang lebih kurang $25{ }^{\circ} \mathrm{C}$ dengan kelembaban sekitar $70 \%$.

Penyiapan Tanaman dan Serangga. Kacang merah (Vigna sinensis (L.) Hassk.) digunakan sebagai tanaman inang $L$. huidobrensis. Benih kacang ditanam dalam polybag dengan tinggi $20 \mathrm{~cm}$ dan diameter 13 $\mathrm{cm}$, sebanyak dua biji per pot. Tanaman muda yang sudah berdaun dua digunakan untuk pemeliharaan lalat pengorok. L. huidobrensis dan parasitoid $H$. varicornis dikoleksi dari lapangan di Cipanas, Cianjur dan dipelihara untuk perbanyakan. Penyediaan serangga inang dilakukan dengan menginfestasikan imago L. huidobrensis pada tanaman yang ditempatkan dalam kurungan kasa (panjang $80 \mathrm{~cm}$, lebar $40 \mathrm{~cm}$, tinggi 65 $\mathrm{cm}$ ) selama 24 jam dan selanjutnya tanaman yang sudah diteluri dipelihara dalam kurungan kasa sampai diperoleh larva instar-2 atau -3 yang siap untuk diparasit. Pemarasitan dilakukan dengan memasukkan tanaman yang berisi larva inang ke dalam kurungan kasa yang sudah berisi parasitoid. Setiap hari inang yang terparasit dikeluarkan dan dimasukkan inang yang baru. Tanaman yang berisikan inang yang sudah terparasit dipelihara dalam kurungan tersendiri. Sekitar 8 hari setelah pemarasitan, daun dipetik dan dimasukkan ke dalam stoples sampai imago muncul. Sebagian imago parasitoid yang muncul dimasukkan ke dalam kurungan perbanyakan dan sebagian yang lain digunakan untuk percobaan. Imago parasitoid baik dalam kurungan pemeliharaan ataupun perlakuan diberi makan madu dengan konsentrasi $10 \%$.

Preferensi pada Instar Inang. Percobaan ini dilakukan dengan tujuan untuk mengetahui instar larva inang yang paling disukai oleh $H$. varicornis untuk meletakkan telur dan untuk pengisapan inang. Pengujian dilakukan terhadap larva instar-2 dan -3 karena dilaporkan bahwa instar ke-1 tidak dipilih oleh parasitoid (Supartha, 1998). Percobaan dilakukan dengan menggunakan kurungan berupa stoples (diameter dan tinggi $14 \mathrm{~cm}$ ) yang bagian bawahnya dilubangi dan diganti dengan kain kasa. Ke dalam satu kurungan stoples dimasukkan dua lembar daun kacang merah yang masing-masingnya terinfestasi larva inang instar -2 atau -3. Masing-masing instar berjumlah sekitar 6-8 larva. Kemudian dilepaskan satu pasang $H$. varicornis (umur 5 hari) selama 24 jam. Parasitoid diberi makan madu $10 \%$ yang dioleskan pada dinding stoples. Setelah 24 jam korokan dibuka, dan dengan bantuan mikroskop banyaknya larva yang mati karena terparasit atau lumpuh dihitung dan dicatat. Percobaan dilakukan dengan 15 pasang $H$. varicornis sebagai ulangan.

Tanggap Fungsional. Daun kacang merah yang terinfestasi larva inang instar-3 dengan kerapatan 1, 4, $6,8,10$, dan 13 larva per daun, dimasukkan secara terpisah ke dalam kurungan stoples. Selanjutnya ke dalam masing-masing stoples dilepaskan satu pasang H. varicornis (umur 5 hari) selama 24 jam. Parasitoid diberi makan madu $10 \%$ dengan mengoleskannya pada dinding stoples. Setelah 24 jam korokan dibuka, dan dengan bantuan mikroskop dan banyaknya larva yang mati karena lumpuh atau terparasit dihitung dan dicatat. Percobaan dilakukan dengan 8-10 pasang parasitoid sebagai ulangan untuk masing-masing kerapatan inang.

Analisis Data. Untuk menguji perbedaan tingkat pelumpuhan dan parasitisasi pada dua instar inang digunakan uji-t pada $\alpha=0.05$ dengan bantuan program MINITAB versi 11 (MINITAB Inc, 1996). Bentuk tanggap fungsional diperiksa dengan regresi logistik antara proporsi inang yang diparasit $(\mathrm{Ne} / \mathrm{No})$ dan kerapatan inang yang tersedia (No) (Juliano, 1993). Data diuji suai pada fungsi polinom hubungan antara Ne/No dan No:

$$
\mathrm{Ne}=\begin{aligned}
& \left(\mathrm{P}_{0}+\mathrm{P}_{1} \mathrm{~N}_{0}+\mathrm{P}_{2} \mathrm{~N}_{0}{ }^{2}+\mathrm{P}_{3} \mathrm{~N}_{0}{ }^{3}\right) \\
& \exp \left(\mathrm{P}_{0}+\mathrm{P}_{1} \mathrm{~N}_{0}+\mathrm{P}_{2} \mathrm{~N}_{0}{ }^{2}+\mathrm{P}_{3} \mathrm{~N}_{0}{ }^{3}\right)
\end{aligned}
$$

dengan $\mathrm{P}_{0}, \mathrm{P}_{1}, \mathrm{P}_{2}$, dan $\mathrm{P}_{3}$ secara berurutan adalah titik potong, koefisien linear, kuadratik, dan kubik. Keempat parameter ini diduga dengan metode kemungkinan maksimum dengan prosedur PROC CATMOD SAS (SAS Institute, 1990). Jika $P_{1}$ bernilai negatif, proporsi inang yang mati menurun sejak awal seiring dengan meningkatnya inang, dan hal ini mencirikan bentuk tanggap fungsional tipe II. Bila $\mathrm{P}_{1}$ bernilai positif dan $\mathrm{P}_{2}$ negatif, proporsi inang yang dimangsa awalnya meningkat dan kemudian menurun, dan hal ini mencirikan tanggap fungsional tipe III (Juliano, 1993). Karena dari analisis regresi logistik diketahui bahwa parameter $\mathrm{P}_{1}$ bernilai negatif, maka hanya tanggap fungsional tipe II yang akan diuraikan modelnya. Untuk memperoleh nilai penduga masa penanganan (Th) dan laju pencarian (a) digunakan model persamaan cakram Holling (Holling, 1959) dan persamaan acak (Rogers, 1972). Untuk tanggap fungsional tipe II, masing-masing persamaan tersebut adalah: 


$$
\begin{gathered}
\mathrm{Ne}=\mathrm{aTNo} /(1+\mathrm{aThNo}) \\
\mathrm{Ne}=\text { No }\{1-\exp [\mathrm{a}(\mathrm{ThNe}-\mathrm{T})]\}
\end{gathered}
$$

$\mathrm{Ne}$, No, Th, dan a seperti disebutkan sebelumnya, sedangkan $\mathrm{T}$ adalah total waktu yang tersedia bagi parasitoid ( $24 \mathrm{jam})$. Nilai penduga parameter diperoleh melalui regresi non-linear menggunakan prosedur PROC NLIN SAS (SAS Institute, 1990) seperti yang dilakukan oleh Juliano (1993).

\section{HASIL DAN PEMBAHASAN}

Preferensi pada Instar Inang. Total rataan banyaknya larva inang yang lumpuh oleh $H$. varicornis secara nyata lebih tinggi $(\mathrm{t}=7,03 ; \mathrm{db}=24 ; \mathrm{P}<0,001)$ pada instar $-3(2,60 \pm 0,25)$ dibandingkan pada instar-2 $(0,47 \pm 0,17)$ (Gambar 1a). Begitu juga rataan banyaknya inang yang diparasit lebih tinggi $(\mathrm{t}=5,25 ; \mathrm{db}=$ 24; $\mathrm{P}<0,001)$ pada instar-3 $(1,00 \pm 0,13)$ dibandingkan pada instar-2 $(0,13 \pm 0,09)$ (Gambar 1b). Hal ini mengisyaratkan bahwa $H$. varicornis lebih memilih inang yang berukuran lebih besar baik pada kegiatan pelumpuhan inang maupun peletakan telur.

Perbedaan preferensi pada instar inang tersebut diduga disebabkan oleh beberapa hal baik yang bersifat kimiawi maupun fisik. Secara kimia, inang yang lebih besar mungkin menghasilkan volatil yang lebih tajam sehingga lebih memudahkan pendeteksiannya oleh parasitoid. Kedua, sebagai parasitoid idiobion, $H$. varicornis perlu memilih inang yang berukuran lebih besar agar dapat menyediakan nutrisi yang cukup dan lengkap untuk kebutuhan perkembangan keturunannya. Secara fisik, pemilihan inang diduga berhubungan dengan stimulus vibrasi pada daun yang dihasilkan oleh larva pengorok, yang digunakan oleh parasitoid sebagai tanda dalam pencarian inangnya (Casas et al., 1998). Inang yang berukuran kecil menghasilkan vibrasi yang rendah sehingga lebih sulit dideteksi oleh parasitoid (Sugimoto, 1977). Selain itu, secara visual ukuran korokan yang dihasilkan larva instar-3 lebih besar dari pada instar-2 sehingga lebih mudah ditemukan oleh imago betina parasitoid (Petitt \& Wietlisbach, 1993).

Fenomena preferensi pada larva inang instar-3 juga dilaporkan untuk spesies parasitoid pengorok daun lainnya. Rustam (2002) mendapatkan tingkat parasitisasi Opius sp. (Hymenoptera: Braconidae) pada larva $L$. huidobrensis instar-3 lebih tinggi dibandingkan pada instar-2. Parasitoid Diglyphus begini (Ashmead) (Hymenoptera: Eulophidae) dilaporkan lebih memilih larva L. trifolii instar-3 (Heinz \& Parella, 1989). Pada L. trifolii tingkat reproduksi dan sintasannya meningkat dengan bertambahnya ukuran larva inang. Selain pada pengorok daun, nimfa yang lebih besar juga lebih disukai untuk meletakkan telur oleh Trioxys pallidus (Hymenoptera: Braconidae), parasitoid dari apid yang menyerang walnut (Rakhshani et al., 2004) Hal yang sama juga terjadi pada Anagyrus sp. (Hymenoptera: Encyrtidae), parasitoid dari Phenacoccus madeirensis Green (Hemiptera: Pseudococcidae) (Chong, 2007). Menurut Quicke (1997) perbedaan ukuran tubuh inang menentukan jumlah dan kualitas makanan yang tersedia bagi parasitoid. Dalam hubungan ini, tingginya tingkat pelumpuhan dan parasitisasi $H$. varicornis pada larva instar-3 diperkirakan terkait dengan pemenuhan nutrisi yang lebih lengkap untuk mencapai reproduksi yang optimal.
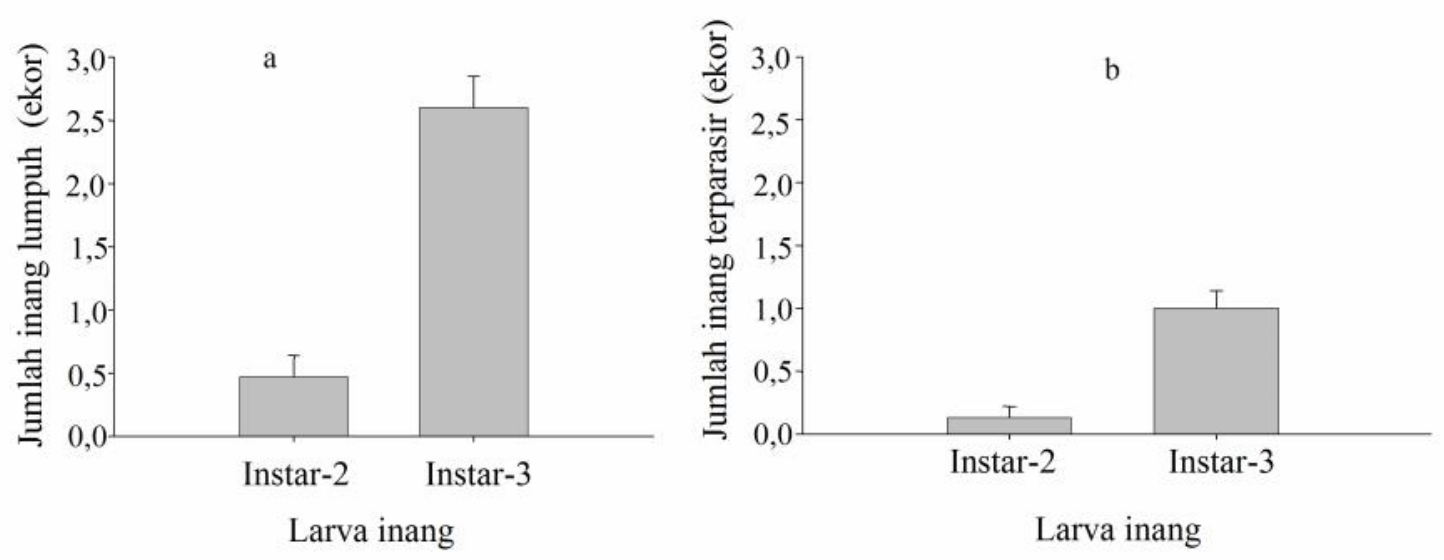

Gambar 1. Perbandingan jumlah inang lumpuh (a) dan terparasit (b) 
Imago betina $H$. varicornis melakukan pelumpuhan permanen pada inangnya. Larva yang lumpuh kemudian dimanfaatkan untuk tempat peletakan telur atau kegiatan pengisapan inang. Hasil penelitian preferensi inang menunjukkan bahwa hanya sebagian kecil dari larva yang lumpuh digunakan untuk peletakan telur (Gambar 1). Dengan demikian mortalitas utama dari larva inang lebih disebabkan oleh kegiatan pelumpuhan. Parasitoid yang menyebabkan kematian inang jauh lebih banyak daripada daya parasitisasinya merupakan agens pengendalian hayati yang baik.

Tanggap Fungsional. Analisis regresi logistik menunjukkan bahwa hubungan antara kelimpahan inang dengan pelumpuhan dan parasitisasi memperlihatkan tanggap fungsional tipe II. Hal ini ditunjukkan oleh koefisien linear yang semuanya bernilai negatif (Tabel 1). Walaupun demikian, nilai penduga koefisien linear untuk parasitisasi tidak berbeda nyata dengan nol (P> $0,05)$, yang mengisyaratkan bahwa penafsiran data perlu dilakukan secara lebih hati-hati.
Untuk pelumpuhan, nilai a dan Th masing-masing 0,038 dan 1,473 pada model persamaan cakram, dan 0,076 dan 2,060 pada model persamaan acak. Untuk kegiatan parasitisasi, nilai a dan Th adalah 0,012 dan 4,649 pada model persamaan cakram, dan 0,014 dan 5,075 pada persamaan acak. Koefisien determinasi $\left(\mathrm{R}^{2}\right)$ pada parasitisasi yang bernilai 0,33 menunjukkan bahwa kegiatan peletakan telur sangat bervariasi pada tiap kerapatan inang (Tabel 2).

Dari Tabel 2 tampak bahwa persamaan cakram memberikan nilai penduga a dan Th yang lebih rendah daripada persamaan acak. Pada persamaan cakram diasumsikan bahwa inang yang tersedia selalu tetap jumlahnya, sedangkan pada persamaan acak banyaknya inang menurun sejalan dengan waktu karena sebagian inang mengalami pelumpuhan dan/atau parasitisasi (Juliano, 1993). Oleh karena itu, untuk seperangkat data tertentu, nilai laju pencarian dan masa penangan yang dibangkitkan oleh model persamaan acak lebih tinggi daripada model persamaan cakram (De Clerq et al., 2000). Pemilihan model tanggap fungsional yang sesuai

Tabel 1. Hasil analisis regresi logistik proporsi larva L. huidobrensis yang lumpuh dan yang terparasit oleh $H$. varicornis pada berbagai kerapatan inang

\begin{tabular}{llcccc}
\hline Faktor kematian & \multicolumn{1}{c}{ Parameter } & Nilai penduga & Galat baku & $\mathrm{X}^{2}$ & $\mathrm{P}$ \\
\hline Pelumpuhan & Titik potong $\left(\mathrm{P}_{0}\right)$ & 7,0209 & 2,9365 & 5,73 & 0,0168 \\
& Linear $\left(\mathrm{P}_{1}\right)$ & $-2,5065$ & 1,1736 & 4,56 & 0,0327 \\
& Kuadratik $\left(\mathrm{P}_{2}\right)$ & 0,3093 & 0,1456 & 4,51 & 0,0336 \\
& Kubik $\left(\mathrm{P}_{3}\right)$ & $-0,0122$ & 0,00563 & 4,67 & 0,0308 \\
Parasitisasi & $-0,7382$ & 1,1187 & 0,44 & 0,5094 \\
& Titik potong $\left(\mathrm{P}_{0}\right)$ & $-0,4780$ & 0,5354 & 0,80 & 0,3720 \\
& Linear $\left(\mathrm{P}_{1}\right)$ & 0,0866 & 0,0779 & 1,24 & 0,2659 \\
& Kuadratik $\left(\mathrm{P}_{2}\right)$ & $-0,00433$ & 0,00338 & 1,64 & 0,1999 \\
\hline
\end{tabular}

Tabel 2. Nilai penduga parameter laju pencarian (a) dan masa penanganan (Th) berdasarkan model persamaan cakram dan acak hubungan antara pelumpuhan dan parasitisasi $H$. varicornis dengan peningkatan kelimpahan inang

\begin{tabular}{ccccccc}
\hline \multirow{2}{*}{ Aktivitas } & \multicolumn{3}{c}{ Persamaan cakram } & \multicolumn{3}{c}{ Persamaan acak } \\
\cline { 2 - 7 } & $\mathrm{a}\left(\mathrm{jam}^{-1}\right)$ & $\mathrm{Th}(\mathrm{jam})$ & $\mathrm{R}^{2}$ & $\mathrm{a}\left(\mathrm{jam}^{-1}\right)$ & $\mathrm{Th}(\mathrm{jam})$ & $\mathrm{R}^{2}$ \\
\hline Pelumpuhan & $0,038 \pm 0.007$ & $1,473 \pm 0.541$ & 0,64 & $0,076 \pm 0.024$ & $2,060 \pm 0.644$ & 0,65 \\
Parasitisasi & $0,012 \pm 0.005$ & $4,649 \pm 0.3615$ & 0,33 & $0,014 \pm 0.006$ & $5,075 \pm 0.3744$ & 0,33 \\
\hline
\end{tabular}

$\mathrm{R}^{2}=1$ - (jumlah kuadrat sisaan/jumlah kuadrat total terkoreksi) 
bagi parasitoid tergantung pada perilaku betina dalam menemukan inangnya. Parasitoid yang mempunyai kemampuan membedakan status inang tidak perlu lagi melakukan pemeriksaan pada inang yang telah terparasit. Untuk parasitoid yang demikian, model acak lebih tepat diterapkan. Sebaliknya, pada parasitoid yang tidak memiliki kemampuan membedakan inang yang terparasit atau tidak, model persamaan cakram dapat diberlakukan (Wang \& Ferro, 1998).

Gambar 2 menunjukkan bahwa banyaknya larva inang yang dilumpuhkan dan yang diletaki telur (terparasit) meningkat dengan bertambahnya kerapatan inang. Pada kerapatan inang tertinggi (13 ekor), banyaknya inang yang dilumpuhkan berkisar antara 3-9 dengan rataan $6,50 \pm 0,80(\mathrm{x} \pm \mathrm{SE})$. Pada kerapatan inang 1 ekor, seluruh larva pada 10 ulangan mengalami pelumpuhan, hal itu menunjukkan bahwa parasitoid $H$. varicornis tergolong efisien dalam menemukan inang pada kerapatan inang rendah. Banyaknya inang yang terparasit berkisar 1-4 ekor dengan rataan $2.5 \pm 0.42$ ekor yang terjadi pada kerapatan inang 10 ekor. Kegiatan pengisapan inang pada parasitoid sinovigenik diperlukan untuk pematangan telur dan bahkan dapat meningkatkan keperidian. Namun demikian, laju oviposisi ditentukan oleh muatan telur (Heimpel \& Rosenheim, 1998). Dalam hal parasitoid H. varicornis laju oviposisi adalah sekitar 2 butir/hari. Terbatasnya muatan telur menyebabkan kurva parasitisasi (b) lebih landai dan lebih cepat mencapai asimtot dibandingkan kurva pelumpuhan (a).

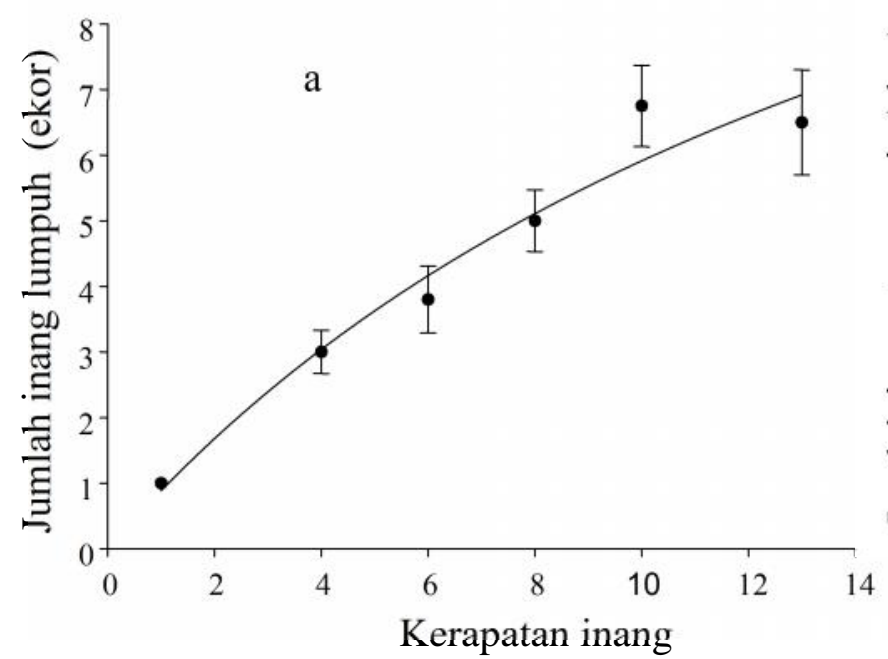

Berdasarkan perilaku model, spesies parasitoid yang memperlihatkan tanggap fungsional tipe II diperkirakan tidak mampu mengatur populasi hama yang menjadi inangnya (Hassell, 2000). Tanggap fungsional tipe II sering dijumpai pada hasil percobaan di laboratorium dengan hanya satu jenis inang yang tersedia. Pada kondisi di laboratorium, parasitoid dipaksa untuk tetap berada dalam satu arena pencarian, sedangkan di lapangan parasitoid dapat meninggalkan satu gugus pencarian dan pindah ke gugus lainnya karena pada gugus sebelumnya kerapatan inang rendah atau sebagian besar inang telah terparasit. Oleh karena itu, tanggap fungsional tipe III diperkirakan lebih umum et al., 2000). Collins et al. (1981) memperlihatkan tanggap fungsional tipe III dari Aphelinus thompsoni Graham (Hymenoptera: Aphelenidae) bila parasitoid ini diberi kesempatan berpindah dari arena percobaan; sebaliknya bila terkungkung bersama inangnya dalam waktu yang tetap, parasitoid memperlihatkan tangggap fungsional tipe II. Selain itu, karakteristik tumbuhan inang juga dapat menentukan bentuk tanggap fungsional. Pada tanaman cabai dan terong, predator Podisus nigrispinus (Dallas) menunjukkan tanggap fungsional tipe II, sedangkan pada tanaman tomat menunjukkan tipe III (De Clercq et al., 2000). Begitu pula Messina \& Hanks (1998) melaporkan bahwa Propylea quatuordecimpunctata (L.) (Coleoptera: Coccinellidae), predator kutu daun, memperlihatkan tipe tanggap fungsional yang berbeda pada dua jenis rumput yang menjadi inang kutu daun.

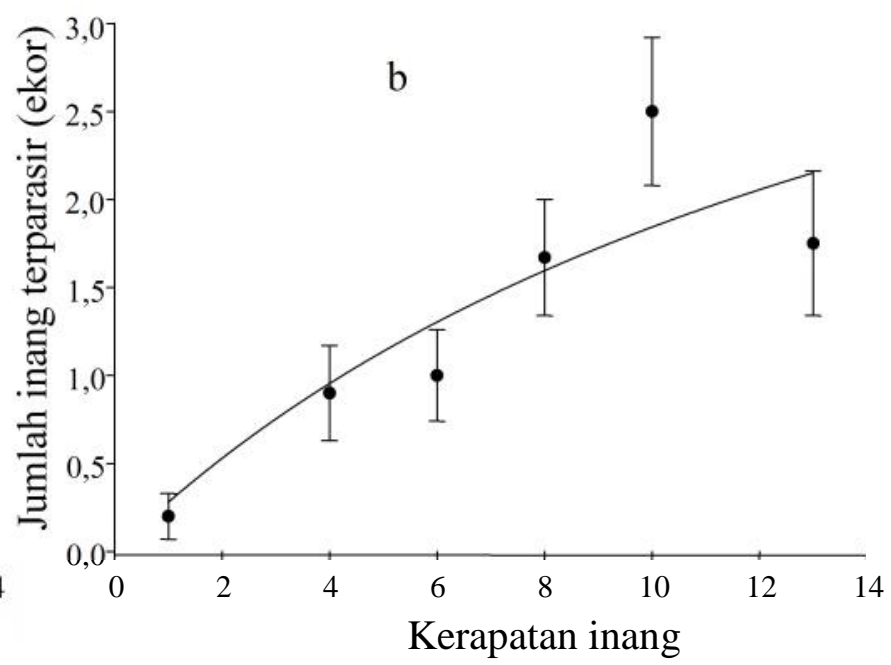

Gambar 2. Jumlah larva pengorok daun yang lumpuh (a) dan terparasit (b) oleh H. varicornis pada berbagai kerapatan inang. Data pengamatan (lambang) dinyatakan sebagai rataan \pm SE, sedangkan nilai dugaan (garis) dibangkitkan dari individu data berdasarkan model cakram, $\mathrm{n}=8-10$ ulangan per kerapatan inang 
Karena lalat $L$. huidobrensis menyerang berbagai jenis sayuran, kiranya menarik untuk dikaji tanggap fungsional $H$. varicornis pada berbagai jenis tumbuhan inang.

Data tanggap fungsional yang diperoleh dari percobaan di laboratorium tidak dapat secara langsung diekstrapolasi pada kondisi nyata di lapangan (De Clercq et al., 2000). Penggunaan tanggap fungsional sebagai kriteria untuk mengevaluasi agens pengendalian hayati perlu selalu dikaitkan dengan tanggap numerik. Hasil penelitian Purnomo (2003) mengungkapkan adanya fenomena tanggap numerik yang ditunjukkan oleh hubungan kelimpahan $H$. varicornis yang meningkat dengan bertambahnya kerapatan larva pengorok daun. Adanya tanggap fungsional dan tanggap numerik mengisyaratkan bahwa parasitoid $H$. varicornis merupakan komponen musuh alami yang penting dalam penekanan lalat pengorok daun kentang.

\section{SIMPULAN}

Imago betina parasitoid $H$. varicornis lebih memilih larva inang instar-3 untuk kegiatan pelumpuhan dan parasitisasi dibandingkan instar-2. Di laboratorium, parasitoid memperlihatkan tanggap fungsional tipe II baik untuk pelumpuhan maupun parasitisasi. Tingginya laju pelumpuhan serta adanya tanggap fungsional dan numerik memberikan indikasi bahwa parasitoid $H$. varicornis merupakan agens pengendalian hayati yang baik dalam pengaturan populasi lalat pengorok daun di lapangan.

\section{DAFTAR PUSTAKA}

Berryman, A.A. 1981. Population Ecology: Theory and Application. Plenum Press. New York.

Casas, J., S. Bacher, J. Tautz, R. Meyhover, \& D. Piere 1998. Leaf Vibrations and Air Movements in a Leafminer-Parasiotid System. Bio. Cont. 11:147153.

Chong, J.H. 2007. Functional Response and Progeny Production of the Madeira Mealybug Parasitoid, Anagyrus sp. Nov.nr.sinope : The Effect of Host Stage Preference. Bio. Cont. 41: 78-85.

Collins, MD, S.A.Ward, \& A.F.G. Dixon. 1981. Handling Time and the Functional Response of Aphelinus thomsoni, a Predator and Parasite of the Aphid Drepanosiphum platanoidis. J. Anim. Ecol. 50: 479-487.
De Clercq, P., J. Mohaghegh, \& L. Tirry. 2000. Effect of Host Plant on the Functional Response of the Predator Podisus nigrispinus (Heteroptera: Pentatomidae). Bio. Cont. 18: 65-70.

Doutt, R.L. 1973. Biological Characteristics of Entomophagous Adults. pp 145-167. In P. De bach (Ed). 1973. Biological Control of Insect Pests and Weeds. Chapman and Hall. London.

Fuester, R.W., \& P.B. Taylor. 1991. Host Instar Prefences and Developmental Times of Two Ichneumonid Parasites of the Gypsy Moth (Lepidoptera: Lymantriidae). Ann. Entomol. Soc. Am. 84(4): 429-435.

Hassell, M. P. 2000. The Spatial and Temporal Dynamics of Host-Parasitoid Interactions. Oxford University Press. New York.

Heimpel, G.E., \& J.A. Rosenheim. 1998. Egg Limitation in Parasitoids: A Review of the Evidence and a Case Study. Bio. Cont. 11: 160-168.

Holling, C.S. 1959. Some characteristics of simple types of predations and parasitism. Canadian Entomol. 91: 385-398.

Heinz, K.M. \& M.P. Parrella. 1990. The Influence of Host Size on Sex Ratios in the Parasitoid Diglyphus begini (Hymenoptera: Eulophidae). Ecol. Entomol. 15: 391-399.

Heinz, K.M. \& M.P. Parrella. 1989. Attack Behavior and Host Size Selection by Diglyphus begini on Liriomyza trifolii in Chrysanthemum. Entomol. Exp. Appl. 53: 147-156.

Juliano, S.A. 1993. Non-linear curve fitting: Predation and Functional Response Curves. Pp. 158-183. In SM Scheiner and J Gurevitch (eds). Design and analysis of ecological experiments. Chapman \& Hall. New York.

Minitab Inc. 2000. MINITAB 11 Statistika Software.

Montoya, P., P. Liedo, B.B. Rey, J.F. Barrera, J. Cancino, \& M. Aluja. 2000. Functional response and superparasitism by Diachasmimorpha longicaudata (Homoptera: Braconidae), a 
parasitoid of fruit flies (Diptera: Tephritidae). Ann. Entomol. Soc. Am. 93 (1): 47-54.

Petitt, F.L. \& D.O. Wietlisbach. 1993. Effect of Host Instar and Size on Parasitization Efficiency and Life History Parameters of Opius dissitus. Entomol. Exp. Appl. 66: 227-236.

Purnomo. 2003. Liriomyza huidobrensis (Blanchard) (Diptera:Agromyzidae): Kesesuaian Inang, Perkembangan Populasi, dan Pengendaliannya. [Disertasi]. Bogor: Institut Pertanian Bogor.

Quicke, D.L.J. 1997. Parasitic Wasps. Chapman \& Hall. London.

Rakhshani, E., A.A. Talebi, N. Kavallieratos, \& Y. Fathipour. 2004. Host Stage Preference, Juvenile Mortality and Functional Response of Trioxys pallidus (Hymenoptera: Braconidae, Aphidiinae). Biologia Bratislava. 59: 197-203.

Rauf, A., B.M. Shepard, \& M.W. Johnson. 2000. Lefminers in Vegetables, Ornamental Plants and Weeds in Indonesia: Survey of Host Crops Species Composition and Parasitoids. Int. J. Pest. Manag. 46: 257-266.

Rogers, D.J. 1972. Random search and insect population models. J. Anim. Ecol. 41: 569-383.
Rustam, R. 2002. Biologi Parasitoid Opius sp (Hymenoptera: Braconidae) pada Hama Pengorok Daun Liriomyza huidobrensis (Blanchard)(Diptera: Agromyzidae) [tesis]. Bogor: Program Pascasarjana, Institut Pertanian Bogor.

SAS Institute. 1990. SAS User's Guide Version 6, Fourth Edition, volume 2. Cary (North Carolina): SAS Institut Inc.

Sugimoto, T. 1977. Ecological Studies on the Relationship between the Ranunculus Leaf Mining fly, Phytomyza ranunculi Schrank (Diptera: Agromyzidae) and its Parasite, Kratochviliana sp (Hymenoptera: Eulophidae) from the Viewpoint of Spatil Structure I. Analysis of Searching and Attacking Behaviours of the Parasite. Appl. Entomol. Zool. 12 (2): 87-103.

Supartha, I.W. 1998. Bionomi Liriomyza huidobrensis (Blanchard) (Diptera: Agromyzidae) pada Tanaman Kentang [Disertasi]. Bogor: Program Pascasarjana, Institut Pertanian Bogor.

Wang, B. \& D.X. Ferro. 1998. Functional Responses of Trichogramma ostriniae (Hymenoptera: Trichogrammatidae) to Ostrinia nubilalis (Lepidoptera: Pyralidae) under Laboratory and Field Conditions. Environ. Entomol. 27 (3): 752758. 